\title{
KAPITAL ZNANJA - TEMELJ KREIRANJA ZNANJA PRI PODJETNIKIH
}

\section{POVZETEK}

$V$ študiji obravnavamo znanje kot ključni konkurenčni vir. Za oblikovanje novega znanja pa je temelj kapital znanja. Nonaka, Toyama in Konno so opredelili štiri dimenzije kapitala znanja. Z analizo smo ugotovili skladnost ugotovljenih kategorij konstrukta kapitala znanja: kapital znanja na podlagi izkušenj, kapital konceptualnega znanja, kapital rutinskega znanja in kapital sistemskega znanja.

Ključne besede: mala in srednja podjetja, konkurenčnost, kapital znanja, kreiranje znanja, izobraževanje odraslih

\section{KNOWLEDGE CAPITAL - FACILITATOR OF KNOWLEDGE CREATION FOR ENTREPRENEURS - ABSTRACT}

This study examines knowledge as a key resource for competitiveness. According to the theory of knowledge creation, knowledge assets are the key elements facilitating the processes of knowledge creation. Nonaka, Toyama and Konno have identified four dimensions of the knowledge capital construct: experimental knowledge assets, conceptual knowledge assets, routine knowledge assets and system knowledge assets. Our analysis confirms their hypothesis.

Keywords: small and medium enterprises (SME), competitiveness, knowledge capital, knowledge creation, adult education

UDK: $330.322 .3: 374.7$

\section{UVOD}

Globalna ekonomija je iz obdobja, ko so aktivnosti temeljile na proizvodnji, prešla $\mathrm{v} \gg$ dobo znanja« (Drucker, 1994), kjer znanje posameznikov in podjetij pomeni vir uspešnosti in dobička (Senoo, Magnier-Watanabe, Salmador, 2007). Znanje, ki je strateški visokokakovostni vir moči (Grant, 1996) in vzvod napredka (Toffer, 1991), omogoča večjo učinkovitost in prilagoditev razmeram na trgu (Miller, Shamsie, 1996) in je pomemben element iskanja poslovnih priložnosti (Autio, Sapienza, Almeida, 2000). Sposobnost kreiranja in uporabe znanja je tako glavni vir konkurenčnih prednosti podjetja (Cyert, Kumar, Williams, 1993; Nonaka, 1991; 1994; Nonaka, Takeuchi, 1995). V povezavi z znanjem raziskovalci poudarjajo tudi pomen človeškega kapitala (Coleman, 1988). Z njim označujemo »zalogo « znanja in veščin (Ireland, Hitt, Sirmon, 2003). Teoriji, ki sta prispevali k dojemanju pomena človeškega kapitala in znanja za organizacijo in njeno strategijo, sta teorija, ki temelji na virih (resource based theory), in teorija, ki temelji na znanju (knowledge based theory). Obe poudarjata pomen intelektualne lastnine $\mathrm{v}$ razmerju do priložnosti podjetja, uresničevanja strategije, doseganja konkurenčnih prednosti oziroma uspešnosti (Barney, 1991; Huggins, Izushi, 2007; Lockett, Thompson, Morgestern, 2009; Penrose, 1959 in drugi). Obe teoriji poudarjata tudi pomen kapitala znanja. Nosilci znanja so posamezniki, ki skupaj uresničujejo poslanstvo in vizijo podjetja (Miller, 2002). V malih podjetjih je podjetnik tisti, ki prepozna poslovne priložnosti, ima vizijo, opredeli cilje in strategijo. Prepoznavanje poslovnih priložnosti je subjektiven proces, delno izražen prek osebnostnih lastnosti podjetnika, delno pa prek njegovega socialnega in intelektualnega kapitala (Scott, Venkataraman, 2000).
Dr. Franc Vidic

Gea College -

Fakulteta za

podjetništvo

Ljubljana 
Za konkurenčno poslovanje $\mathrm{v}$ dinamičnem okolju je pomembno odzivanje na izzive in kreiranje novega znanja. Temelj za kreiranje novega znanja je kapital znanja. V prvem delu članka podajamo povzetke proučevane znanstvene in strokovne literature s področja kreiranja znanja in kapitala znanja. V drugem delu predstavljamo rezultate empirične analize, ki temelji na podatkih, pridobljenih z raziskavo konstrukta, ki je bila opravljena med slovenskimi podjetniki.

\section{KREIRANJE ZNANJA IN KAPITAL ZNANJA}

Znanje je strateški vir, združuje veščine in sposobnosti posameznikov, tima, organizacije, usmerjenih v reševanje problemov. Nonaka, Toyama in Konno (2000) ga definirajo kot: »specifično premoženje organizacije, ki omogoča kreiranje konkurenčne in dodane vrednosti«. Znanje je izredno kompleksno. Davenport in Prusak (1998) ga opredeljujeta kot spreminjajoč se nabor izkušenj, vrednot, kontekstualnih informacij, lastnih prepričanj, ki sestavljajo okvir vrednotenja in vključevanja novih spoznanj in informacij. Znanje ni le zbir podatkov in informacij (Davenport, Prusak, 1998), nastane, ko se podatki in informacije procesirajo in kontekstualizirajo v socialni interakciji med posamezniki in organizacijami ter ko jih posameznik interpretira (Nonaka, Takeuchi, 1995; Nonaka, Toyama, Konno, 2000; Chou, He, 2004). Znanje je shranjeno v organizaciji oziroma se v njej pretaka (Dierickx, Cool, 1989, v Thornhill, 2006).

Obstaja več klasifikacij znanja (Matusik, Hill, 1998), pogosto ga delimo na eksplicitno in tacitno (Nonaka, 1991; Polanyi, 1966). Tacitno znanje je kontekstualno specifično za posameznika in ga je od posameznika, ki je nosilec znanja, težko oddvojiti in posredovati
(Davenport, Merchnad, 1999). Nasprotno pa lahko eksplicitno znanje hranimo, kodiramo, zbiramo in posredujemo. Tacitno znanje se pretaka $\mathrm{v}$ eksplicitno in obratno skozi procese socializacije, eksternalizacija, kombinacije in internalizacije (Nonaka, Takeuchi, 1995).

Za zagotavljanje konkurenčnosti moramo znanje zbirati, kreirati in uporabljati. Kreiranje znanja (knowledge creation) je proces, ki omogoča razvoj znanja (Nonaka, Takeuchi, 1995). Proces kreiranja znanja lahko vključuje elemente podjetniške in tržne naravnanosti; ti se pretvorijo $\mathrm{v}$ kapital znanja (Li, Huang, Tsai, 2009). V članku smo se osredotočili na teorijo dinamičnega kreiranja znanja (Nonaka, Takeuchi, 1995). Jedro teorije je kontekstualizacija načinov pretakanja med tacitnim in eksplicitnim znanjem med posamezniki, skupinami ter podjetji (Nonaka, Takeuchi, 1995).

Znanje je dinamično - vključuje kontekst, metode in okolje, ki omogoča socialno interakcijo med posamezniki pri preoblikovanju tacitnega v eksplicitno znanje (Chou, He, 2004). Teorija organizacijskega kreiranja znanja temelji na štirih procesih (SECI): socializacija, eksternalizacija, kombinacija in internalizacija (Nonaka, 1991; 1994; Nonaka, Takeuchi, 1995), katerim pa je podlaga kapital znanja (Nonaka, Toyama, Konno, 2000). Količina znanja v organizaciji je odvisna od vnosa (vhoda), diseminacije (izhoda) in moderatorjev/aktivistov procesov kreiranja znanja (Nonaka, Takeuchi, 1994). Kapital znanja je specifično premoženje, ki omogoča kreiranje konkurenčne dodane vrednosti (Nonaka, Toyama, Konno, 2000). Za lažje razumevanje kapitala znanja in njegove vloge $v$ procesu kreiranja novega znanja predlagajo Nonaka, Toyama, Nagata in Konno (Nonaka, Toyama, Nagata, 2000; Nonaka, Toyama, Konno, 2000) delitev v štiri različne 
skupine: 1. kapital znanja na podlagi izkušenj (experimental knowledge assets), 2. kapital konceptualnega znanja (conceptual knowledge assets), 3. kapital rutinskega znanja (routine knowledge assets), 4. kapital sistemskega znanja (systemic knowledge assets). Povezanost posameznih skupin s procesom kreiranja SECI sta potrdila Chou in He (2004) kot tudi Chou in Chang (2004).

Kapital znanja na podlagi izkušenj vključuje tacitno znanje, ki se širi z neposrednim posredovanjem in skupnimi izkušnjami posameznikov. Veščine in znanje posameznikov se prenašajo med zaposlenimi, kupci, dobavitelji kot tudi med osebami v povezanih podjetjih (Chou, He, 2004). Kapital na podlagi izkušenj (Nonaka, Toyama, Konno, 2000) vključuje veščine posameznikov - »know how « posameznikov. Obstajajo pa še druge oblike znanja: emocionalno znanje kot na primer skrb, ljubezen, zaupanje; psihično znanje kot na primer gestikulacija, obrazno pojasnjevanje; energično znanje kot na primer sposobnost preživetja, entuziazem in usmerjenost; ritmično znanje, ki omogoča improvizacijo in vstop. Glede na to, da je to znanje težko posnemati, zbirati, vrednotiti in tržiti (Chou, He, 2004), ima pomembno vlogo pri oblikovanju konkurenčnih prednosti organizacije. Raziskave Becera-Fernandezove in Sabherwala (2003) kažejo, da je ta oblika znanja pomembna $\mathrm{v}$ procesu internalizacije, to je procesa, ko posamezniki zbirajo znanje z opazovanjem in pogovorom $\mathrm{z}$ drugimi.

Kapital konceptualnega znanja vključuje eksplictno znanje, ki se izraža v simbolih, znakih, jeziku in drugih oblikah, na primer $\mathrm{v}$ dizajnu in konceptu izdelkov (Nonaka, Toyama, Konno, 2000). Njegova vrednost temelji na percepciji strank in zaposlenih v podjetju. Na primer vrednost blagovne znamke je odvisna od percepcije strank. Kapital konceptualnega znanja je opredeljen, enostavno ga artikuliramo, vključuje elemente, ki se lahko uporabijo pri oblikovanju novih izdelkov. Konceptualno znanje se uredi v eksplicitno obliko v procesu eksternalizacije. Eksternalizacija se začne, ko posamezniki poskušajo prikazati svoje znanje skozi analogije, metafore oziroma reševanje problemov (Becera-Fernandez, Sabherwal, 2003). Skozi ta proces postaja znanje bolj sprejemljivo in razumljivo drugim članom skupine. Kapital konceptualnega znanja omogoča natančnejšo, osredotočeno specializacijo na posameznem področju (znati kaj oziroma deklarativno znanje).

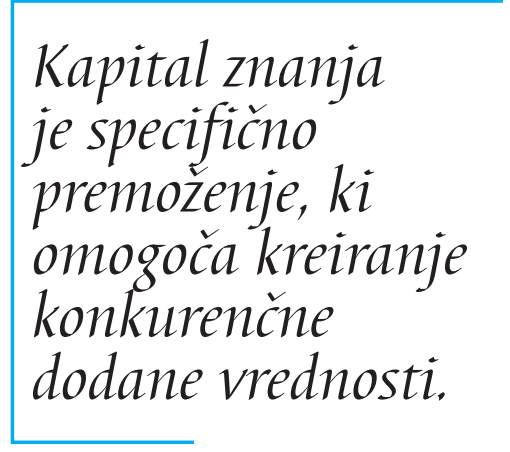

$\mathrm{V}$ naslednji fazi se to znanje sistematizira $\mathrm{v}$ kapital sistemskega znanja, uredi se v eksplicitno obliko z natančno specifikacijo, priročniki, datotekami (Nonaka, Toyama, Konno, 2000). Znanje postane vidno in oprijemljivo. Kapital sistemskega znanja vključuje tudi pravno zaščiteno intelektualno lastnino, kot so patenti, licence in drugi uradni dokumenti. Prenos sistematiziranega kapitala znanja je enostaven, saj je to znanje primerno za posredovanje posameznikom in skupinam. Lahko se tudi izmenjuje in kombinira. Definicija procesa kombinacije (Nonaka, Takeuchi, 1995) je preoblikovanje kompleksnega znanja $\mathrm{v}$ bolj kompleksno in sistemsko urejeno eksplicitno znanje. V smislu pretvorbe znanja se eksplicitno znanje zbira $v$ organizaciji in zunaj nje ter kombinira, ureja in procesira $\mathrm{v}$ novo znanje (Chou, He, 2004). Kombinacija je proces upravljanja deklarativnega znanja s ciljem kombiniranja glede na zastavljene cilje.

Eksplicitno znanje se v nadaljevanju internalizira in postane del kapitala rutinskega znanja, na primer »know-how«: pri vsakodnevnem delu, rutini, organiziranosti in 
kulturi organizacije. $\mathrm{V}$ tem primeru imamo opravka s tacitnim znanjem organizacije, ki temelji na ustaljenih aktivnostih in praksi pri vsakodnevnem delu (Nonaka, Toyama, Konno, 2000). Prevladuje procesno znanje. Pri opredelitvi kapitala rutinskega znanja velja, da člani organizacije prenašajo, povezujejo in nadaljujejo obstoječo prakso v razmišljanju in aktivnostih. Socializacija je proces preoblikovanje novega tacitnega znanja skozi prenašanje izkušenj. Znanje, ki ga želimo izmenjevati enote v podjetju so bolj osredotočene, imajo podrobnejše cilje in višjo stopnjo specializacije; kadar pa nastopajo skupaj, so cilji širše zasnovani, zahtevajo več sodelovanja in izmenjave znanja (Kusonaki, Nonaka, Nagata, 1998).

Chou in He (2004) sta proučevala vpliv različnih oblik znanja v posameznih fazah procesa kreiranja znanja SECI (socializacija, eksternalizacija, kombinacija in internalizacija).

Tabela 1: Povezava med modelom kreiranja znanja (SECI) in kapitalom znanja

\begin{tabular}{|l|l|l|}
\hline $\begin{array}{l}\text { Področje/ } \\
\text { naravnanost }\end{array}$ & Osredotočeno & Široko \\
\hline Vsebina & $\begin{array}{l}\text { ksternalizacija } \\
\text { (kapital konceptualnega znanja) }\end{array}$ & $\begin{array}{l}\text { Kombinacija } \\
\text { (apital sistemskega znanja) }\end{array}$ \\
\hline Procesi & $\begin{array}{l}\text { Internalizacija } \\
\text { (kapital znanja na podlagi izkušenj) }\end{array}$ & $\begin{array}{l}\text { Socializacija } \\
\text { (apital rutinskega znanja) }\end{array}$ \\
\hline
\end{tabular}

Vir: Chou, He (2004)

skozi socializacijo, je časovno in prostorsko omejeno na delo, izkušnje ... Socializacija pomeni združevanje znanja iz različnih virov in disciplin (Chou, He, 2004).

Kapital znanja se spreminja in je rezultat dinamičnih procesov, ki potekajo sočasno s socialno interakcijo med posamezniki (Chou, He, 2004). Glede na posameznika je znanje specifično, saj informacije dobijo pomen in postanejo uporabne $\mathrm{v}$ kontekstu interpretacije in uporabe pri posamezniku. Za doseganje ciljev in izvajanje različnih nalog potrebuje organizacija različne oblike znanja. Chou in He (2004) sta glede na cilje in naloge opredelila dve obliki znanja: naravnanost na vsebino in naravnanost na procese. Naravnanost na vsebino je osredotočenje na izpolnitev specifičnih ciljev. Naslanja se na specifične dele oziroma izdelke, ki jih želi podjetje izboljšati. Po drugi strani pa je naravnanost na procese pomembna pri razvoju izdelkov, na primer pri njihovem oblikovanju. Posamezne
Glede na različne vrste znanja sta ugotovila vpliv kapitala konceptualnega znanja na proces eksternalizacije in vpliv kapitala rutinskega znanja na proces socializacije. Kapital znanja na podlagi izkušenj se ni izkazal kot kapital z velikimi učinki na proces internalizacije pri kreiranju znanja, podobno tudi kapital sistemskega znanja nima posebnega vpliva na proces kombinacije.

Hipoteza $H_{0}$ : Kapital znanja sestavljajo štiri različne oblike, kapital znanja na podlagi izkušenj, kapital konceptualnega znanja, kapital rutinskega znanja in kapital sistemskega znanja, ki podpirajo procese kreiranja znanja.

\section{METODOLOGIJA DELA}

Nonaka, Toyama in Konno (2000) so opredelili štiri oblike kapitala znanja, ki podpirajo procese kreiranja znanja SECI (socializacija, eksternalizacija, kombinacija in internalizacija) (Nonaka, Takeuchi, 1995). Da bi potrdili 
ugotovitve avtorjev, smo opravili raziskavo med slovenskimi podjetniki.

$\mathrm{K}$ sodelovanju $\mathrm{v}$ raziskavi smo povabili 2.500 podjetnikov in direktorjev malih in srednjih podjetij iz Slovenije $\mathrm{z}$ več kot šest in manj kot 250 zaposlenimi. Predpostavljali smo, da se bo del direktorjev z veseljem odzval na povabilo ter izpolnil in vrnil pravilno izpolnjene anketne liste. Glede na izkušnje smo pričakovali 200 vrnjenih vprašalnikov, kar bi zadostilo priporočilu avtorjev Hair, Black, Babin in Anderson (2010), ki pravijo, da mora biti za izvedbo faktorske analize na razpolago več kot sto enot. Uporabili smo metodo anketiranja po pošti. Pri oblikovanju vprašalnika in tehnologije zbiranja podatkov smo sledili metodologiji in nasvetom, ki jih za raziskave po pošti in internetu daje Dillman (2000).

Respondenti so vrnili 203 vprašalnike, osem izmed njih ni bilo popolnih in smo jih izločili. Preostalih 195 smo uporabili za nadaljnjo kvantitativno analizo. Podjetja, ki so vrnila vprašalnike, so iz različnih panog in različnih velikosti. Primerjava strukture poslanih
$\mathrm{Z}$ raziskavo smo preverjali štiri dimenzije konstrukta kapitala znanja: kapital znanja na podlagi izkušenj, kapital rutinskega znanja, kapital konceptualnega znanja in kapital sistemskega znanja (Nonaka, Toyama, Konno, 2000). Posamezne oblike kapitala smo preverjali z desetimi trditvami, ki sta jih razvila Chou in He (2004). Respondente smo spraševali, v kolikšni meri se strinjajo z navedenimi trditvami. Uporabljena je bila petstopenjska Likertova lestvica, pri kateri ocena 1 pomeni nikakor se ne strinjam, ocena 5 pa popolnoma se strinjam.

\section{DESKRIPTIVNA ANALIZA POSAMEZNIH KONSTRUKTOV KAPITALA ZNANIA}

Kapital znanja na podlagi izkušenj smo preverjali z desetimi trditvami, največje strinjanje so respondenti izkazali pri trditvi »Zaposleni želijo prenašati svoje izkušnje«, srednja aritmetična sredina odgovorov je 3,94, najpogostejši odgovor je »se strinjam « (38,9 odstotka), standardni odklon 0,946 pa kaže na razpršenost odgovorov okoli sredinske vrednosti.

Tabela 2: Primerjava med poslanimi in vrnjenimi vprašalniki glede na število zaposlenih

\begin{tabular}{|l|l|l|l|l|}
\cline { 2 - 5 } \multicolumn{2}{c|}{} & \multicolumn{2}{l|}{ Poslani vprašalniki } & \multicolumn{2}{l|}{ Vrnjeni vprašalniki } \\
\hline Število zaposlenih & Frekvenca & Delež $(v \%)$ & Frekvenca & Delež (v \%) \\
\hline $6-9$ & 968 & 38,72 & 57 & 28,64 \\
\hline $10-19$ & 853 & 34,12 & 62 & 31,16 \\
\hline $20-49$ & 480 & 19,20 & 46 & 23,12 \\
\hline $50-99$ & 129 & 5,16 & 24 & 12,06 \\
\hline $100-250$ & 70 & 2,80 & 10 & 5,02 \\
\hline Brez odgovora & & & $(4)$ & \\
\hline SKUPAJ & 2.500 & 100 & $199(203)$ & 100 \\
\hline
\end{tabular}

Vir: lastna raziskava

in vrnjenih vprašalnikov glede na število zaposlenih je prikazana v Tabeli 2.
Naslednja trditev z najvišjo stopnjo strinjanja je »Zaposleni so pripravljeni prenašati svoje povzetke opažanj - izkušenj«. Aritmetična 
sredina vseh odgovorov je 3,91, standardni odklon je podoben kot pri prejšnji trditvi, in sicer 0,947 . Najmanjše strinjanje pa so poka- klon kaže manjšo razpršenost odgovorov okoli sredinske vrednosti. Največ odgovor je »se strinjam«(47,3 odstotka), nekoliko

Tabela 3: Aritmetične sredine, standardni odkloni, asimetričnost in sploščenost za oceno kapitala znanja na podlagi izkušenj

\begin{tabular}{|l|l|l|l|l|l|l|l|}
\hline Kapital znanja na podlagi izkušenj & $\mathrm{n}$ & $\mathrm{AS}$ & $\mathrm{SO}$ & $\mathrm{Skew}$ & $\mathrm{SE}$ & Kurt & SE \\
\hline $\begin{array}{l}\text { Zaposleni so pripravlieni prenašati svoje povzetke opažani - } \\
\text { izkušenj. }\end{array}$ & 199 & 3,91 & 0,947 & $-0,729$ & 0,172 & 0,202 & 0,343 \\
\hline Zaposleni želijo prenašati svoje izkušnje. & 200 & 3,94 & 0,946 & $-0,660$ & 0,172 & $-0,087$ & 0,342 \\
\hline $\begin{array}{l}\text { Zaposleni so pripravlieni pojasniti svoja čustva, kot sta skrb in } \\
\text { liubezen. }\end{array}$ & 199 & 3,18 & 1,062 & $-0,215$ & 0,172 & $-0,666$ & 0,343 \\
\hline $\begin{array}{l}\text { Zaposleni so se pripravljeni zaupati liudem v drugih delovnih } \\
\text { skupinah. }\end{array}$ & 198 & 3,21 & 1,014 & $-0,042$ & 0,173 & $-0,384$ & 0,344 \\
\hline $\begin{array}{l}\text { Zaposleni so pripravlieni zbirati in shranjevati znanje, pridobl- } \\
\text { jeno z izkušnjami pri delu. }\end{array}$ & 199 & 3,68 & 0,920 & $-0,458$ & 0,172 & $-0,220$ & 0,343 \\
\hline Zaposleni so pripravljeni predstaviti svoj entuziazem. & 198 & 3,46 & 0,932 & $-0,257$ & 0,173 & $-0,398$ & 0,344 \\
\hline Zaposleni so pripravljeni vsem predstaviti svoje improvizacije. & 198 & 3,45 & 1,000 & $-0,273$ & 0,173 & $-0,483$ & 0,344 \\
\hline Vrednote organizacije so del vsakega izmed zaposlenih. & 194 & 3,85 & 0,962 & $-0,507$ & 0,175 & $-0,357$ & 0,347 \\
\hline $\begin{array}{l}\text { V podjetju je jasno skomuniciran pomen varovanja pridoblje- } \\
\text { nih izkušenj. }\end{array}$ & 197 & 3,55 & 0,928 & $-0,297$ & 0,173 & $-0,104$ & 0,345 \\
\hline Zaposleni so pripravljeni inovirati. & 199 & 3,65 & 0,968 & $-0,697$ & 0,172 & 0,394 & 0,343 \\
\hline
\end{tabular}

Legenda: $\mathrm{n}$ - število odgovorov, AS - aritmetična sredina na lestvici od 1 do 5 ( 1 pomeni, da se s trditvijo nikakor ne strinjajo, 5 pomeni, da se popolnoma strinjajo); SO - standardni odklon; Skew - (skewness) koeficient asimetričnosti porazdelitve (glede na normalno porazdelitev); Kurt - (kurtosis) koeficient sploščenosti porazdelitve (glede na normalno porazdelitev); SE - standardna napaka. Enaka legenda velia pri naslednjih tabelah.

Vir: lastna raziskava

zali pri trditvi »Zaposleni so pripravljeni pojasniti svoja čustva, kot sta skrb in ljubezen«, kjer je aritmetična sredina 3,18, odgovori pa so kar precej razpršeni okoli sredinske vrednosti, standardni odklon je 1,062.

Kapital rutinskega znanja smo preverili z desetimi trditvami. Najvišjo stopnjo strinjanja respondentov ima trditev »Usposabljanje z delom in učenje sta vrednoti zaposlenih «. Aritmetična sredina vseh odgovorov je 4,00, standardni odklon pa 0,816 . Standardni od- manj pa »zelo se strinjam« (27,6 odstotka). Naslednji trditvi z visoko stopnjo strinjanja sta: »Pri zajemanju in prenosu znanja pričakujemo visoko stopnjo sodelovanja med zaposlenimi« in »Kultura organizacije in njeni cilji so jasno opredeljeni in znani vsem zaposlenim«. Aritmetični sredini odgovorov na trditvi sta 3,97 oziroma 3,96. Najmanjše strinjanje je bilo pri trditvi »Podjetje omogoča interakcije in prenos novega znanja prek meja organizacije«. Aritmetična sredina vseh odgovorov je 3,16. 
Tudi kapital konceptualnega znanja smo preverili z ugotavljanjem stališč, vsak izmed respondentov je izrazil stopnjo strinjanja z de- pri trditvi »Podjetje ima določeno ekipo za izvajanje promocije blagovne znamke« in »Podjetje ima določeno ekipo za promocijo

Tabela 4: Aritmetične sredine, standardni odkloni, asimetričnost in sploščenost za oceno kapitala rutinskega znanja

\begin{tabular}{|l|l|l|l|l|l|l|l|}
\hline Kapital rutinskega znanja & $\mathrm{n}$ & $\mathrm{AS}$ & $\mathrm{SO}$ & $\mathrm{Skew}$ & $\mathrm{SE}$ & Kurt & SE \\
\hline $\begin{array}{l}\text { V podjetju pripravljamo navodila, priročnike za izvajanje } \\
\text { vsakodnevnega dela. }\end{array}$ & 199 & 3,10 & 1,263 & $-0,054$ & 0,172 & $-1,019$ & 0,343 \\
\hline $\begin{array}{l}\text { Zaposleni se zavedajo pomena znanja pri vsakodnevnem } \\
\text { rutinskem delu. }\end{array}$ & 200 & 3,73 & 0,934 & $-0,634$ & 0,172 & 0,237 & 0,342 \\
\hline Zaposleni so pripravljeni iskati/pridobivati novo znanje. & 200 & 3,85 & 0,863 & $-0,548$ & 0,172 & 0,246 & 0,342 \\
\hline $\begin{array}{l}\text { Obstoječi načini razmišljanja in aktivnosti v podjetju so rezul- } \\
\text { tat stalnega izpopolnjevanja. }\end{array}$ & 199 & 3,71 & 0,934 & $-0,563$ & 0,172 & 0,155 & 0,343 \\
\hline $\begin{array}{l}\text { Pri zajemanju in prenosu znanja pričakujemo visoko stopnjo } \\
\text { sodelovanja med zaposlenimi. }\end{array}$ & 200 & 3,97 & 0,888 & $-0,803$ & 0,172 & 0,530 & 0,342 \\
\hline \begin{tabular}{l} 
Usposabljanje z delom in učenje sta vrednoti zaposlenih. \\
\hline Zaposleni so vrednoteni na podlagi svojih izkušenj.
\end{tabular} & 199 & 4,00 & 0,816 & $-0,619$ & 0,172 & 0,327 & 0,343 \\
\hline $\begin{array}{l}\text { Zaposleni so se pripravljeni pogovarjati o svojih izkušnjah z } \\
\text { liudmi iz drugih delovnih skupin. }\end{array}$ & 199 & 3,68 & 0,845 & $-0,397$ & 0,172 & 0,135 & 0,343 \\
\hline $\begin{array}{l}\text { Podjetje omogoča interakcije in prenos novega znanja prek } \\
\text { meja organizacije. }\end{array}$ & 198 & 3,16 & 1,064 & $-0,072$ & 0,173 & $-0,544$ & 0,344 \\
\hline $\begin{array}{l}\text { Kultura organizacije in njeni cilji so jasno opredeljeni in znani } \\
\text { vsem zaposlenim. }\end{array}$ & 199 & 3,96 & 0,915 & $-0,600$ & 0,172 & $-0,236$ & 0,343 \\
\hline
\end{tabular}

Vir: lastna raziskava

setimi trditvami. Najvišjo stopnjo strinjanja med respondenti ima trditev »Zaposleni so se pripravljeni učiti na napakah«. Aritmetična sredina vseh odgovorov je 4,03, standardni odklon pa 0,846 . Standardni odklon kaže na nekoliko manjšo razpršenost. $\mathrm{S}$ trditvijo se strinja 48,8 odstotka respondentov, 28,1 odstotka pa se z njo zelo strinja. Visoko stopnjo strinjanja so respondenti izkazali tudi pri trditvi »Zaposleni so pripravljeni inovirati in nadomeščati zastarelo znanje «. Aritmetična sredina odgovorov je 3,82, standardni odklon pa 0,944 . Strinjanja pa niso izrazili konceptov oziroma oblik, novih izdelkov/ storitev «. V prvem primeru je aritmetična sredina vseh odgovorov 2,93, v drugem pa 2,98. Standardni odklon v obeh primeri kaže na veliko razpršenost odgovorov okoli sredinske vrednosti.

Kapital sistemskega znanja smo preverili z desetimi trditvami (Tabela 5). Najvišjo stopnjo strinjanja med respondenti ima trditev »Podjetje ima zgledno urejeno dokumentacijo o svojih izdelkih «. Aritmetična sredina vseh odgovorov je 3,89, standardni odklon pa 
Tabela 5: Aritmetične sredine, standardni odkloni, asimetričnost in sploščenost za oceno kapitala konceptualnega znanja

\begin{tabular}{|l|l|l|l|l|l|l|l|}
\hline Kapital konceptualnega znanja & $\mathrm{n}$ & $\mathrm{AS}$ & $\mathrm{SO}$ & $\mathrm{Skew}$ & $\mathrm{SE}$ & Kurt & SE \\
\hline $\begin{array}{l}\text { Podjetje predstavlja svoje oblikovne atribute z dizajnom, } \\
\text { simboli in pojasnili. }\end{array}$ & 198 & 3,45 & 1,025 & $-0,262$ & 0,173 & $-0,495$ & 0,344 \\
\hline $\begin{array}{l}\text { Podjetje prikazuje lastnosti izdelkov z njihovim imidžem, } \\
\text { simboli in pojasnili. }\end{array}$ & 197 & 3,48 & 1,100 & $-0,406$ & 0,173 & $-0,488$ & 0,345 \\
\hline $\begin{array}{l}\text { Podjetje izkazuje kapital blagovne znamke z imidžem, simbo- } \\
\text { li in pojasnili. }\end{array}$ & 197 & 3,42 & 1,083 & $-0,367$ & 0,173 & $-0,395$ & 0,345 \\
\hline $\begin{array}{l}\text { Zaposleni so pripravljeni sodelovati z drugimi (npr. partnerii, } \\
\text { strankami) pri vrednotenju posameznih elementov dizajna. }\end{array}$ & 196 & 3,37 & 1,012 & $-0,352$ & 0,174 & $-0,237$ & 0,346 \\
\hline $\begin{array}{l}\text { Zaposleni so pripravljeni sodelovati z drugimi (npr. partnerii, } \\
\text { strankami) pri vrednotenju značilnosti izdelkov. }\end{array}$ & 197 & 3,48 & 1,003 & $-0,686$ & 0,173 & 0,261 & 0,345 \\
\hline $\begin{array}{l}\text { Zaposleni so pripravljeni sodelovati z drugimi (npr. partnerii, } \\
\text { strankami) pri ocenjevanju vrednosti blagovne znamke. }\end{array}$ & 196 & 3,41 & 1,016 & $-0,533$ & 0,174 & $-0,014$ & 0,346 \\
\hline $\begin{array}{l}\text { Zaposleni so pripravljeni inovirati in nadomeščati zastarelo } \\
\text { znanje. }\end{array}$ & 198 & 3,82 & 0,944 & $-0,763$ & 0,173 & 0,411 & 0,344 \\
\hline Zaposleni so se pripravljeni učiti na napakah. & 195 & 4,03 & 0,846 & $-0,926$ & 0,174 & 1,119 & 0,346 \\
\hline $\begin{array}{l}\text { Podjetje ima določeno ekipo za izvajanje promocije blagov- } \\
\text { ne znamke. }\end{array}$ & 193 & 2,93 & 1,356 & 0,057 & 0,175 & $-1,154$ & 0,348 \\
\hline $\begin{array}{l}\text { Podjetje ima določeno ekipo za promocijo konceptov oziro- } \\
\text { ma oblik, novih izdelkov/storitev. }\end{array}$ & 194 & 2,98 & 1,302 & $-0,085$ & 0,175 & $-1,102$ & 0,347 \\
\hline
\end{tabular}

Vir: lastna raziskava

1,071. Standardni odklon kaže na precejšnjo razpršenost merjenih vrednosti okoli sredinske vrednosti. S trditvijo se strinja 37,4 odstotka respondentov, 31,5 odstotka pa se jih $\mathrm{z}$ njo zelo strinja. Zelo majhno razliko v stopnji strinjanja so respondenti izrazili pri trditvi »Vrednotenje in zaščita znanja sta nalogi vsakega v podjetju «. Aritmetična sredina vrednosti merjenih stališč je 3,88, standardni odklon oziroma razpršenost okoli sredinske vrednosti pa je nekoliko večja kot v prejšnjem primeru. Najnižjo stopnjo strinjanja so respondenti izrazili pri trditvi »V podjetju imamo omejen dostop do nekaterih virov znanja«. Aritme- tična sredina vseh vrednosti je 2,96, standardni odklon 1,331. Standardni odklon kaže na veliko razpršenost merjenih vrednosti okoli sredinske vrednosti.

\section{KONSTRUKT KAPITALA ZNANIA}

Konstrukt kapitala znanja se nanaša na stališča vodstev anketiranih organizacij, saj so na vprašalnik odgovarjali menedžerji oziroma podjetniki. Ocena normalnosti spremenljivk je pokazala, da je razmerje standardnih 
Tabela 6: Aritmetične sredine, standardni odkloni, asimetričnost in sploščenost za oceno kapitala sistemskega znanja

\begin{tabular}{|c|c|c|c|c|c|c|c|}
\hline Kapital sistemskega znanja & $n$ & AS & so & Skew & SE & Kurt & SE \\
\hline Podjetje ima zgledno urejeno dokumentacijo o svojih izdelkih. & 196 & 3,89 & 1,071 & $-0,939$ & 0,174 & 0,387 & 0,346 \\
\hline $\begin{array}{l}\text { Podjetje omogoča enostaven dostop do podatkov o izdelkih } \\
\text { oziroma njihovih katalogov. }\end{array}$ & 197 & 3,79 & 1,148 & $-0,891$ & 0,173 & 0,019 & 0,345 \\
\hline $\begin{array}{l}\text { Uporaba intelektualne lastnine organizacije je mogoča le z } \\
\text { avtorizacijo. }\end{array}$ & 192 & 3,29 & 1,317 & $-0,112$ & 0,175 & $-1,133$ & 0,349 \\
\hline $\begin{array}{l}\text { Znanje organizacije je zaščiteno pred nepooblaščeno upora- } \\
\text { bo v podjetju. }\end{array}$ & 195 & 3,23 & 1,264 & $-0,201$ & 0,174 & $-0,959$ & 0,346 \\
\hline $\begin{array}{l}\text { Znanje organizacije je zaščiteno pred nepooblaščeno upora- } \\
\text { bo zunaj organizacije. }\end{array}$ & 195 & 3,46 & 1,297 & $-0,423$ & 0,174 & $-0,920$ & 0,346 \\
\hline $\begin{array}{l}\text { Znanje organizacije je zaščiteno pred dostopom nepooblaš- } \\
\text { čenih v podjetju. }\end{array}$ & 196 & 3,49 & 1,196 & $-0,439$ & 0,174 & $-0,677$ & 0,346 \\
\hline $\begin{array}{l}\text { Znanje organizacije je zaščiteno pred nepooblaščenim do- } \\
\text { stopom vseh zunaj organizacije. }\end{array}$ & 194 & 3,60 & 1,188 & $-0,538$ & 0,175 & $-0,582$ & 0,347 \\
\hline V podjetju imamo omejen dostop do nekaterih virov znanja. & 196 & 2,96 & 1,331 & $-0,083$ & 0,174 & $-1,148$ & 0,346 \\
\hline Vrednotenje in zaščita znanja sta nalogi vsakega v podjetju. & 197 & 3,88 & 1,104 & $-0,973$ & 0,173 & 0,393 & 0,345 \\
\hline Ljudje so jasno informirani o pomenu varovanja znanja. & 195 & 3,61 & 1,122 & $-0,555$ & 0,174 & $-0,381$ & 0,346 \\
\hline
\end{tabular}

Vir: lastna raziskava

napak asimetrije in sploščenosti vsake spremenljivke znotraj želenih vrednosti. Vse vrednosti so nižje od 2 oziroma višje -2 . Ugotovili smo, da ima podatkovna matrika zadostno število korelacij, da je Bartletov preizkus sferičnosti, ki statistično preverja korelacije med spremenljivkami, pokazal, da ima korelacijska matrika značilne korelacije (stopnja prostosti $=0,000$ ). Mera primernosti vzorčenja KMO pa ima vrednost 0,910. Bartletov preizkus in ugotavljanje primernosti vzorčenja KMO upravičujeta uporabo eksplorativne faktorske analize.

Eksplorativno faktorsko analizo smo izvedli s programskim paketom SPSS. Najprej smo pregledali komunalitete in ugotovili, da nobena izmed vrednosti ni nižja od 0,300 . V naslednjem koraku smo izločili spremenljivko »Vrednote podjetja so del vsakega izmed zaposlenih «, ker je bila njena utež naložena na več faktorjih. Spremenljivki »Zaposleni so se pripravljeni učiti na napakah « in »Podjetje ima zgledno urejeno dokumentacijo o svojih izdelkih« pa smo izločili, ker sta bili močno naloženi na napačnih faktorjih.

Pri izboru števila faktorjev smo upoštevali teoretična izhodišča, grafični prikaz (scree plot), lastno vrednost (eigenvalue) in delež pojasnjene variance (total variance explained). Grafični prikaz je pokazal, da je možno število faktorjev 
Tabela 7: Matrika (pattern matrix) in uteži posameznih spremenliivk za dimenzijo kapital znanja

\begin{tabular}{|c|c|c|c|c|c|c|c|}
\hline & \multicolumn{7}{|l|}{ Faktor } \\
\hline & 1 & 2 & 3 & 4 & 5 & 6 & 7 \\
\hline $\begin{array}{l}\text { Podjetje ima določeno ekipo za promocijo konceptov oziroma } \\
\text { oblik, novih izdelkov/storitev. }\end{array}$ & 0,962 & & & & & & \\
\hline $\begin{array}{l}\text { Podjetje ima določeno ekipo za promocijo konceptov oziroma } \\
\text { oblik, novih izdelkov/storitev. }\end{array}$ & 0,753 & & & & & & \\
\hline $\begin{array}{l}\text { Zaposleni so se pripravlieni zaupati ljudem v drugih delovnih sku- } \\
\text { pinah. }\end{array}$ & & 0,739 & & & & & \\
\hline Zaposleni so pripravljeni vsem predstaviti svoje improvizacije. & & 0,731 & & & & & \\
\hline $\begin{array}{l}\text { Zaposleni so pripravljeni pojasniti svoja čustva, kot sta skrb in } \\
\text { ljubezen. }\end{array}$ & & 0,661 & & & & & \\
\hline Zaposleni so pripravlieni predstaviti svoj entuziazem. & & 0,646 & & & & & \\
\hline $\begin{array}{l}\text { Zaposleni so pripravljeni zbirati in shranjevati znanje, dobljeno z } \\
\text { izkušnjami pri delu. }\end{array}$ & & 0,441 & & & & 0,308 & \\
\hline $\begin{array}{l}\text { Podjetje omogoča interakcije in prenos novega znanja prek meja } \\
\text { organizacije. }\end{array}$ & & 0,394 & & & & & \\
\hline Zaposleni so pripravljeni inovirati. & & 0,346 & & & & & \\
\hline $\begin{array}{l}\text { Znanje podjetja je zaščiteno pred dostopom nepooblaščenih v } \\
\text { podjetju. }\end{array}$ & & & 0,903 & & & & \\
\hline $\begin{array}{l}\text { Znanje podjetja je zaščiteno pred nepooblaščeno uporabo zunaj } \\
\text { podjetja. }\end{array}$ & & & 0,869 & & & & \\
\hline $\begin{array}{l}\text { Znanje podjetja je zaščiteno pred nepooblaščenim dostopom vseh } \\
\text { zunaj podjetja. }\end{array}$ & & & 0,850 & & & & \\
\hline $\begin{array}{l}\text { Znanje podjetja je zaščiteno pred nepooblaščeno uporabo v pod- } \\
\text { jetju. }\end{array}$ & & & 0,789 & & & & \\
\hline V podjetju imamo omejen dostop do nekaterih virov znanja. & & & 0,566 & & & & \\
\hline Ljudje so jasno informirani o pomenu varovanja znanja. & & & 0,512 & & & 0,326 & \\
\hline $\begin{array}{l}\text { Uporaba intelektualne lastnine podjetja je mogoča le z } \\
\text { avtorizacijo. }\end{array}$ & & & 0,459 & & & & \\
\hline Vrednotenje in zaščita znanja sta nalogi vsakega v podjetju. & & & 0,436 & & & 0,363 & \\
\hline $\begin{array}{l}\text { Zaposleni so pripravljeni sodelovati z drugimi (npr. partnerii, stran- } \\
\text { kami) pri vrednotenju značilnosti izdelkov. }\end{array}$ & & & & 0,792 & & & \\
\hline $\begin{array}{l}\text { Zaposleni so pripravljeni sodelovati z drugimi (npr. partnerii, stran- } \\
\text { kami) pri vrednotenju posameznih elementov dizajna. }\end{array}$ & & & & 0,755 & & & \\
\hline $\begin{array}{l}\text { Zaposleni so pripravljeni sodelovati z drugimi (npr. partnerii, stran- } \\
\text { kami) pri ocenjevanju vrednosti blagovne znamke. }\end{array}$ & & & & 0,708 & & & \\
\hline Zaposleni so pripravljeni inovirati in nadomeščati zastarelo znanje. & & & & 0,318 & & 0,301 & \\
\hline
\end{tabular}




\begin{tabular}{|c|c|c|c|c|c|c|c|}
\hline & \multicolumn{7}{|c|}{ Faktor } \\
\hline & 1 & 2 & 3 & 4 & 5 & 6 & 7 \\
\hline $\begin{array}{l}\text { Podjetje prikazuje lastnosti izdelkov z njihovim imidžem, simboli in } \\
\text { pojasnili. }\end{array}$ & & & & & $-0,835$ & & \\
\hline $\begin{array}{l}\text { Podjetje izkazuje kapital blagovne znamke z imidžem, simboli in } \\
\text { pojasnili. }\end{array}$ & & & & & $-0,773$ & & \\
\hline $\begin{array}{l}\text { Podjetje predstavlja svoje oblikovne atribute } z \text { dizajnom, simboli in } \\
\text { pojasnili. }\end{array}$ & & & & & $-0,742$ & & \\
\hline $\begin{array}{l}\text { V podjetju pripravljamo navodila, priročnike za izvajanje vsa- } \\
\text { kodnevnega dela. }\end{array}$ & & & & & $-0,330$ & & \\
\hline $\begin{array}{l}\text { Podjetje omogoča enostaven dostop do podatkov o izdelkih oziro- } \\
\text { ma njihovih katalogov. }\end{array}$ & & & & & & & \\
\hline Usposabljanje z delom in učenje sta vrednoti zaposlenih. & & & & & & 0,778 & \\
\hline $\begin{array}{l}\text { Pri zajemanju in prenosu znanja pričakujemo visoko stopnjo sode- } \\
\text { lovanja med zaposlenimi. }\end{array}$ & & & & & & 0,539 & \\
\hline Zaposleni so pripravljeni iskati/pridobivati novo znanje. & & 0,308 & & & & 0,500 & \\
\hline $\begin{array}{l}\text { Obstoječi načini razmišljanja in aktivnosti v podjetju so rezultat } \\
\text { stalnega izpopolnjevanja. }\end{array}$ & & & & & & 0,482 & \\
\hline $\begin{array}{l}\text { Zaposleni se zavedajo pomena znanja pri vsakodnevnem rutin- } \\
\text { skem delu. }\end{array}$ & & 0,305 & & & & 0,474 & \\
\hline Zaposleni so vrednoteni na podlagi svojih izkušenj. & & & & & & 0,425 & \\
\hline $\begin{array}{l}\text { Kultura podjetja in njegovi cilji so jasno opredeljeni in znani vsem } \\
\text { zaposlenim. }\end{array}$ & & & & & & 0,393 & \\
\hline $\begin{array}{l}\text { V podjetju je jasno skomuniciran pomen varovanja pridobljenih } \\
\text { izkušenj. }\end{array}$ & & 0,307 & & & & 0,327 & \\
\hline $\begin{array}{l}\text { Zaposleni so se pripravljeni pogovarjati o svojih izkušnjah z liudmi } \\
\text { iz drugih delovnih skupin. }\end{array}$ & & & & & & 0,307 & \\
\hline Zaposleni želijo prenašati svoje izkušnje. & & & & & & & $-0,754$ \\
\hline $\begin{array}{l}\text { Zaposleni so pripravljeni prenašati svoje povzetke opažani - izku- } \\
\text { šenj. }\end{array}$ & & & & & & & $-0,702$ \\
\hline
\end{tabular}

Legenda: V tabeli so vpisane vrednosti, višje od 0,300. Uporabljeni sta bili metoda maksimalne verjetnosti (maximum likelihood factoring) in metoda poševne rotacije (oblique factor rotation).

Vir: lastna raziskava

od pet do osem, nakar se krivulja močno položi. Lastno vrednost nad 1 je imelo sedem faktorjev. Odločili smo se za sedem faktorjev, ti pojasnijo več kot 69,5 odstotka variance začetne lastne vrednosti (initial eigenvalues) oziroma 62,8 od- stotka variance ekstrakcijskih seštevkov kvadratov uteži (extraction sum of squared loadings).

Ohranjene spremenljivke dimenzije konstrukta kapitala znanja, ki so se pokazale v 
eksplorativni faktorski analizi, prikazuje Tabela 7, združene so po sedmih faktorjih. Dobljeni faktorji so skladni s teoretičnim konceptom dimenzij kapitala znanja. Dimenzijo kapitala na podlagi izkušenj prikazujeta faktorja F2 in F7. Faktor F2 združuje sedem spremenljivk, faktor F7 pa dve spremenljivki. Glavne značilnosti dimenzije kapitala konceptualnega znanja prikazujejo trije faktorji: F1, F2 in F3. Faktor F1 združuje dve spremenljivki, faktor F4 štiri spremenljivke in faktor F5 pet spremenljivk. Dimenzijo kapitala sistemskega znanja najbolje ponazori faktor F3, ki združuje osem spremenljivk. Dimenzijo rutinskega znanja pa najbolj zastopa faktor F6, ki vključuje devet spremenljivk.

Veljavnost celotnega konstrukta kapitala znanja smo potrdili s konfirmativno faktorsko analizo. Analiza je pokazala dobro zanesljivost (Cronbach $\alpha=0,95)$. Cronbachov koeficient $\alpha$ je najpogostejša mera za ugotavljanje zanesljivosti kazalnikov. Zanesljivost merjenja označimo kot zgledno, če je Cronbachov koeficient $\alpha$ večji od 0,70 (Hair in drugi, 2010). Preverjali smo še druge indekse primernosti modela: statistika $\chi 2, \mathrm{CFI}, \mathrm{RMSEA}$, NFI, RHO. Indeks primernosti modela statistika $(\chi 2=1060,69)$ pri 540 stopnjah prostosti in koeficientu zanesljivosti $(\mathrm{P}=0,00)$ kaže na primernost modela. Enako velja za indeks CFI (comparative fit index), ki je sicer med najbolj uporabljanimi in ima vrednosti med 0 in 1 . Višje vrednosti pomenijo boljši model; lahko rečemo, da je model dober, če je vrednost višja od 0,9 . V našem primeru je CFI enak 0,96. Indeks RMSEA (root mean square error of aproximation) je kazalec, ki poleg vrednosti izraža tudi interval zaupanja za to vrednost. $\mathrm{V}$ našem primeru je vrednost indeksa 0,07 . Nižja absolutna vrednost pomeni boljšo veljavnost modela (Hair in drugi, 2010). Indeks NFI (normed fit index) ima lahko vrednosti med 0 in 1 , vrednosti blizu
1 kažejo na boljši model. V našem primeru je vrednost indeksa 0,93. Enako velja za indeks RHO (reliability coefficient), v našem primeru je njegova vrednost 0,97 . Seveda pa ni absolutnega kriterija, ki bi zagotavljal vrednosti indeksov dobrega konstrukta modela, vrednosti indeksov so le vodilo (Hair in drugi, 2010: 705). Vrednosti, ki so povezane s sprejemljivostjo modela, se spreminjajo glede na razmere in so odvisne od velikosti vzorca, števila merjenih spremenljivk in komunalitet posameznih faktorjev. Preprost način, kako ločiti dober model od slabega, je uporaba več indeksov hkrati. Običajno trije ali štirje koeficienti zadoščajo, da se odločimo o veljavnosti modela. V našem primeru veljavnost konstrukta lahko potrdimo.

V skladu s teoretičnimi izhodišči in opravljenimi analizami lahko hipotezo $\gg H_{0}: \mathrm{Ka}$ pital znanja sestavljajo štiri različne oblike: kapital znanja na podlagi izkušenj, kapital konceptualnega znanja, kapital rutinskega znanja in kapital sistemskega znanja, ki podpirajo procese kreiranja znanja.« potrdimo.

\section{SKLEP}

Kapital znanja je temelj teorije organizacijskega kreiranja znanja (Nonaka, Takeuchi, 1995). Znanje se kreira s pretakanjem tacitnega in eksplicitnega znanja (Nonaka, 1991), in sicer v procesu socializacije, eksternalizacije, kombinacije in internalizacije. Vsi procesi se odvijajo na podlagi kapitala znanja. Različnim procesom daje podlago kapital znanja (Nonaka, Toyama, Konno, 2000). Avtorji so opredelili štiri oblike znanja oziroma dimenzije konstrukta kapitala znanja: kapital znanja na podlagi izkušenj, kapital konceptualnega znanja, kapital rutinskega znanja in kapital sistemskega znanja. Vsaka oblika znanja ima svoje značilnosti in različno podpira po- 
samezne procese kreiranja znanja. S študijo na vzorcu 195 obdelanih vprašalnikov, ki je vključevala eksplorativno in konfirmativno analizo, smo potrdili obstoj več dimenzij konstrukta kapitala znanja med podjetniki v Sloveniji.

Za podjetnike kot tudi za graditev podporne mreže za razvoj podjetništva je pomembno oblikovanje učečega se okolja, kjer so na razpolago različne oblike znanja in kjer so posamezniki nosilci znanja odprti za posredovanje, izmenjavo in kreiranje znanja.

Raziskava prinaša delček v mozaiku informacij, potrebnih za oblikovanje celostne kompleksne slike kreiranja novega znanja; ta mozaik je treba še dopolniti. Poleg tega pa je treba raziskavo razširiti v mednarodno okolje.

\section{LITERATURA IN VIRI}

Autio, E., Sapienza, H. J., Almeida, J. G. (2000). Effects of age at entry, knowledge intensity, and immutability on international growth. Academy of management journal, 43: 909-924.

Barney, J. (1991). Firm resources and sustained competitive advantage. Journal of Management, 17: 99-120.

Becerra-Fernadez, I., Sabherval, R. (2003). Organizational knowledge management: contingency perspective. Journal of management information systems, 18 (1): 35-55.

Chou, S. W., Chang (2006). A contingency model of knowledge creation. The tenth Pacific Asia conference on information systems (PACIS, 2006). Dostopno na: http://aisel.aisnet.org/pacis2006/11 (2.2.2013)

Chou, S.W., He, M.Y. (2004). Knowledge management: the distinctive role of knowledge assets in facilitating knowledge creation. Journal of information science, 30 (2): 146-159.

Coleman, J.S. (1988). Sociological and economic approaches to the analysis of social structure. The American journal of sociology, 94: 95-120.

Cyert, R. M., Kumar, P., Williams, R. J. (1993). Information, market imperfections and strategy. Strategic management journal, 11: 47-58.

Davenport, T., Merchand, D. (1999). Is KM just good information management? Data, information and knowledge are points along a continuum. Dostopno na: http://providersedge.com/docs/ km_articles/is_km_just_good_information_management.pdf (14. 4. 2013).

Davenport, T., Prusak, L. (1998). Know what you know. CIO, 11 (9): 58-63.

Dillman, D. A. (2000). Mail and internet surveys: the tailored design method. New York: John Wiley.

Drucker, P. F. (1994). The theory of the business. Harvard business school, 1994: 96-104.

Drucker, P. F. (2009). A Century of Social Transformation: Emergence of Knowledge Society. V: Managing in a Time of Great Change. Boston: Harvard Business Press.

Grant, R. M. (1996). Grant, toward a knowledge-based theory of the firm. Strategic management journal, 17: 93-107.

Hair, J. F., in drugi (2010). Multivariate data analysis. New York: Pearson-Prentice Hall publisher.

Huggins, R., Izushi, H. (2007). Competing for knowledge. Creating, connecting and growing. Abingdon: Routledge.

Ireland, R. D., Hitt, M. A., Sirmon, D. G. (2003). A model of strategic entrepreneurship: the construct and its dimensions. Journal of management, 29 (6): 963-989.

Kusonaki, K., Nonaka, I., Nagata, A. (1998). Organizational capatibilities in product development of Japanese firms: a conceptual framework and empirical findings. Organizational science, 9(6): 699-718.

Li, Y. H., Huang, J. W., Tsai, M. T. (2009). Entrepreneurial orientation and firm performance: the role of knowledge creation process. Industrial marketing management, 38: 440-449.

Lockett, A., Thompson, S. \& Morgenstern, U. (2009). The development of the resource-based 
view of the firm: a critical appraisal. International journal of management reviews, 10 (1): 9-28.

Matusik, S. F., Hill, C. W. L. (1998). The utilization of contingent work, knowledge creation and competitive advantage. Academy of management review, 23(1): 680-697.

Miller, K. D. (2002). Knowledge inventories and managerial myotopia. Strategic management journal, 23: 689-706.

Miller, D., Shamsie, J. (1996). The resource-based view of the firm in two environments: The Hollywood film studios from 1936 to 1965 . Academy of management journal, 39: 519-543.

Nonaka, I. (1994). A dynamic theory of organizational knowledge creation. Organization science, 5 (1): 14-37.

Nonaka, I. (1991). The knowledge-creating company. Harvard business review, 69: 96-105.

Nonaka, I., Takeuchi, H. (1995). The knowledgecreating company. Oxford: Oxford University Press.

Nonaka, I., Toyama, R., Konno, N. (2000). SECI, ba and leadership: a unified model of dynamic knowledge creation. Long range planning, 33 (1): 5-34.

Nonaka, I., Toyama, R., Nagata A. (2000). A firm as a knowledge-creating entity: a new perspective on the theory of the firm. Industrial and corporate change, 9 (1): 1-20.

Penrose, E., (1959). Limits to the Growth and Size of Firms. The American economic review, 45 (2): 531-543.

Polanyi, M. (1966). The tacit dimension. Chicago: The University of Chicago Press.

Toffer, A. (1991). Powershift: knowledge, wealth and power at the edge of the 21st century. New York: Bantam.

Scott, S., Venkataraman, S. (2000). The promise of entrepreneurship as a field of research. Academy of management review, 25 (1): 217-226.

Senoo, D., Magnier-Watanabe, R., Salmador, M. P. (2007). Workplace reformation, active ba and knowledge creation. From conceptual to a practical framework. European journal of management, 10 (3): 296-315.
Thornhill, S. (2006). Knowledge, innovation and firm performance in high- and low-technology regines. Journal of business venturing, 21: 687-703. 